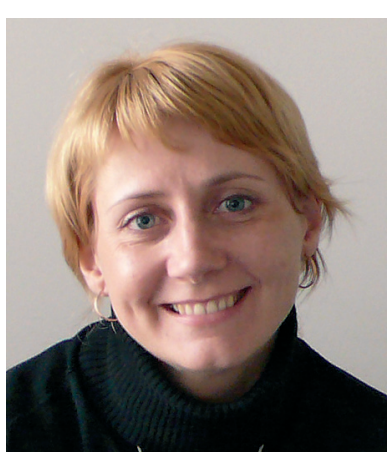

С.А.Рачина ${ }^{1}$, Р.С.Козлов ${ }^{1}$, Е.П.Шаль ${ }^{1}$, И.В.Устюжканин ${ }^{1}$, 0.И.Кречиков ${ }^{1}$, Н.В.Иванчик ${ }^{1}$, И.В.Гудков ${ }^{1}$, 0.Ю.Асафьева ${ }^{2}$, И.А.Гучев ${ }^{3}$, С.А.Гуляева ${ }^{4}$, Ю.В.Бурдинская ${ }^{5}$, С.Б.Яиышина ${ }^{6}$, Т.С.Астахова ${ }^{7}$, Я.Б.Бейкин ${ }^{7}$, Л.Г.Беседина Структура бактериальных возбудителей внебольничной пневмонии в многопрофильных стационарах Смоленска

1 - ГОУ ВПО "Смоленская государственная медицинская академия Федерального агентства по здравоохранению и социальному развитию", 214019, Смоленск, ул. Крупской, 28;

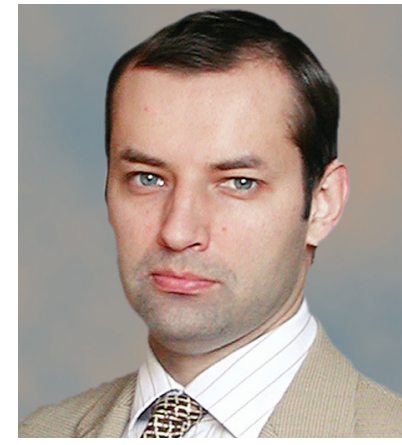

2 - МЛПУ "Клиническая больница скорой медицинской помощи": 214014, Смоленск, ул. Тенишевой, 11;

3 - ФГУ "421-й Военный госпиталь Московского военного округа": 214012, Смоленск, ул. Фрунзе, 35;

4 - МЛПУ "Первая городская клиническая больница": 214006, Смоленск, ул. Фрунзе, 40;

5 - НУ3 "Отделенческая больница ст. Смоленск ОАО РЖД": 214025, Смоленск, 1-й Краснофлотский пер., 15;

6 - ФГУН "ЦНИИ эпидемиологии Роспотреб̈надзора": 111123, Москва, ул. Новогиреевская, 3а;

7 - МУ "Клинико-диагностический центр": 620142, Екатериноург, ул. Декабристов, 38

S.A.Rachina, R.S.Kozlov, E.P.Shal, I.V.Ustyuzhanin, O.I.Krechikov, N.V.Ivanchik, I.V.Gudkov, O.Yu.Asafyeva, I.A.Guchev, S.A.Gulyaeva, Yu.V.Burdinskaya, S.B.Yatsyshina, T.S.Astakhova, Ya.B.Beykin, L.G.Besedina

\title{
A spectrum of causative bacterial pathogens in community- acquired pneumonia in multidisciplinary hospitals of Smolensk
}

Key words: community-acquired pneumonia, etiology, adults, inpatients.

Ключевые слова: внебольничная пневмония, этиология, взрослые госпитализированные пациенты.

В основе рационального выбора антимикробных препаратов (АМП) для эмпирической терапии внебольничной пневмонии (ВП) лежит знание спектра ключевых возбудителей. Однако качественные исследования этиологии ВП в России до сих пор немногочисленны, что связано с комплексом нижеследующих объективных и субъективных факторов:

- существующая территориальная и / или организационная разобщенность микробиологических лабораторий и лечебных подразделений, приводящая к несоблюдению сроков и правил хранения и транспортировки образцов;

- недостаточное оснащение микробиологических лабораторий, использование устаревших подходов к идентификации возбудителей и определению их чувствительности к АМП;

- низкая микробиологическая "культура" медицинского персонала, затрудняющая как правильное получение клинического материала, так и интерпретацию полученных результатов.

По данным Минздравсоцразвития России, у $90 \%$ больных, умерших от ВП в стационаре, этиологический диагноз остается неустановленным [1]. Вследствие дефицита отечественных данных по этиологии ВП стратегия выбора АМП для эмпирической терапии у взрослых нередко основывается на результатах европейских и североамериканских исследований [2]. Однако экстраполяция данных зарубежных исследований имеет определенные ограничения, т. к. не учитывает особенности популяции пациентов с ВП в России (распространенность вредных привычек, частоту и структуру сопутствующих заболеваний и т. д.), характер оказания медицинской помощи, в частности, высокую частоту госпитализации лиц с нетяжелым течением ВП, географическое расположение и климатические условия.

Так, например, анализируя результаты недавно завершившегося крупного проспективного исследования этиологии ВП, исследователи пришли к выводу, что с учетом спектра возбудителей и профиля их антибиотикорезистентности оптимальным режимом АБТ для стационаров Австралии является комбинация бензилпенициллина с доксициклином или макролидами [3]. В то же время значительная часть этих пациентов, в соответствии с североамериканскими или европейскими рекомендациями, должна была бы получать $\beta$-лактамный АМП более широкого спектра действия (цефалоспорин II-III поколения, ингибиторозащищенный пенициллин) либо респираторный фторхинолон [4, 5].

Целью исследования было изучение структуры бактериальных возбудителей ВП у взрослых пациентов, госпитализированных в многопрофильные стационары Смоленска, с использованием различных методов диагностики; анализ вероятности выявления различных микроорганизмов с учетом возраста, хронических сопутствующих заболеваний, тяжести и характера течения заболевания. 


\section{Материалы и методы}

Исследование проводилось на базе 5 ЛПУ: Смоленская областная клиническая больница (СОКБ), муниципальные ЛПУ "Клиническая больница скорой медицинской помощи" (КБСМП) и "Первая городская клиническая больница" (ГКБ № 1), некоммерческое учреждение здравоохранения "Отделенческая больница ст. Смоленск" ОАО РЖД (ЖДБ) и Федеральное государственное учреждение "421-й Военный госпиталь Московского военного округа" (СВГ).

В исследование проспективно включались пациенты с клиническим диагнозом внебольничная пневмония, которые на момент поступления нуждались в стационарном лечении и соответствовали следующим критериям:

1) возраст $\geq 18$ лет;

2) наличие продуктивного кашля;

3) инфильтрация в легких, выявляемая при рентгенологическом исследовании (рентгенографии или рентгеноскопии) органов грудной клетки (ОГК), соответствующая диагнозу пневмония;

4) продолжительность АБТ по поводу данного эпизода ВП < 24 ч или документированная неэффективность предшествующей терапии на амбулаторном этапе.

Критерии исключения:

1) любая госпитализация в течение 14 дней до появления данного эпизода пневмонии;

2) развитие заболевания $>48$ ч с момента госпитализации;

3) проживание в доме престарелых / интернате $\geq 14$ дней.

У всех пациентов до назначения системных АМП или в как можно более ранние сроки с момента госпитализации (не позднее 24 ч) собирался образец свободно отделяемой или индуцированной мокроты; при наличии клинических показаний - жидкости бронхоальвеолярного лаважа (БАЛ). В случае тяжелого течения ВП помимо мокроты забирались 2 образца венозной крови из разных периферических вен для культурального исследования. Правила получения клинического материала соответствовали общепринятым [6].

В случае фатальной ВП выполнялось микробиологическое исследование аутопсийного материала (биоптаты легочной ткани, кровь из полости сердца, ткань печени). Аутопсийный материал отбирался в течение 24 ч после смерти.

Клинические образцы и аутопсийный материал в как можно более короткие сроки доставлялись в микробиологическую лабораторию НИИ антимикробной химиотерапии с соблюдением общепринятых правил транспортировки [6, 7].

Респираторные образцы и биоптаты легочной ткани после доставки в лабораторию делились на 2 части, одна их которых использовалась для культурального исследования, другая - для исследования методом полимеразной цепной реакции (ПЦР).

Образцы мокроты окрашивались по Граму с последующей бактериоскопией для оценки качества образца и определения преобладающего морфотипа бактерий согласно стандартным процедурам [6, 8, 9]. Для выделения аэробных и факультативно-анаэробных микроорганизмов выполнялся посев клинического и аутопсийного материала на селективные и дифференциально-диагностические среды: кровяной агар, шоколадный агар, агар МакКонки, агар для выделения энтерококков и желточно-солевой агар. Культурально исследовались только те образцы мокроты, в которых под малым увеличением микроскопа при просмотре не менее 10 полей зрения было выявлено $\geq 25$ полиморфно-ядерных лейкоцитов и $<10$ эпителиальных клеток. Для культивирования легионелл использовалась коммерческая среда Legionella agar base (HIMEDIA). Культивированию на данной питательной среде подвергались все респираторные образцы, независимо от результатов бактериоскопии мокроты, БАЛ, аутопсийного материала.

Чашки с кровяным и шоколадным агаром инкубировали в течение 20-24 ч при температуре $35^{\circ} \mathrm{C}$ в атмосфере с повышенным (5\%) содержанием $\mathrm{CO}_{2}$. Чашки с селективными средами инкубировали в аэробных условиях при температуре $35^{\circ} \mathrm{C}$. Идентификация аэробных и факультативно-анаэробных микроорганизмов проводилась в соответствии со стандартными методами и процедурами [6, 8, 9].

ПЦР для выявления ДНК Mycoplasma pneumoniae, Chlamydophila pneumoniae и Legionella pneumophila выполнялась с использованием коммерческих тестсистем "АмплиСенс ${ }^{\circledR}$ Legionella pneumophila-FL" вариант FRT и "АмплиСенст Mycoplasma pneumoniae / Chlamydophila pneumoniae-FL" вариант FRT [10].

У части пациентов после подписания формы письменного информированного согласия забирались образцы венозной крови для серологического исследования (10 мл на каждый образец). Первый образец забирался в течение 5 дней с момента госпитализации пациента, 2-й - через 28-35 сут. после получения 1-го.

Серологическая диагностика выполнялась на базе Клинико-диагностического центра г. Екатеринбурга и основывалась на определении в образцах сыворотки при помощи непрямого иммуноферментного анализа (ELISA) антител к 3 видам возбудителей ВП: в парных сыворотках - M. pneumoniae (IgM, $\operatorname{IgA}, \operatorname{IgG})$, C. pneumoniae (IgM, IgG), L. pneumophila (IgM, IgG); в одиночных сыворотках - M. pneumoniae (IgM, IgA), C. pneumoniae (IgM), L. pneumophila (IgM).

Для серологических исследований использовались следующие тест-системы: "Sero MP $\alpha$ IgM", "Sero $\mathrm{MP} \alpha \operatorname{IgA}$ и "Sero MP $\alpha$ IgG; "Sero CP $\alpha$ IgM и "Sero $\mathrm{CP} \alpha$ IgG Savyon Diagnostics (Израиль); Legionella Pneumophila Serogroup 1 ELISA IgM и IgG Vircell, s.1. (Испания). Исследования и интерпретацию полученных результатов проводили согласно методическим рекомендациям к коммерческим наборам [11, 12]. Значимым являлось выявление антител класса IgM к C. pneumoniae, L. pneumophila, IgM и / или IgA к M. pneumoniae в одиночной или хотя бы в 1 из парных сывороток, либо сероконверсия (т. е. измене- 
ние отрицательного результата на положительный) в парных сыворотках при выявлении антител класca IgG.

На каждого пациента, включенного в исследование, заполнялась специально разработанная индивидуальная регистрационная карта (ИРК), в которой указывались демографические характеристики, анамнез заболевания, предшествующая АБТ по поводу данного эпизода ВП, факторы риска инфекции, вызванной L. pneumophila (групповой характер заболевания, путешествие $<1$ мес. до начала заболевания, наличие кондиционера дома / на работе, проживание в гостинице $<1$ мес. до эпизода ВП, посещение бассейна $\geq 1$ раза в неделю, нарушение сознания, связанное с ВП), сопутствующие заболевания, вредные привычки, клинико-рентгенологическая и лабораторная характеристики течения заболевания, результаты микробиологического исследования, осложнения и исход лечения ВП.

Статистическая обработка данных выполнялась в системе SAS (программный пакет SAS института, США, версия 8.2) и с помощью компьютерной программы M-lab, разработанной отделом информационных технологий НИИАХ СГМА. Описательная статистика выполнялась для всех анализируемых показателей в зависимости от типа переменной (качественный, количественный) для группы в целом и каждого ЛПУ отдельно. Проверка количественных признаков на нормальность распределения осуществлялась с использованием критерия Шапиро-Уилка. Проверка гипотезы о равенстве дисперсий проводилась с помощью критерия Левена. Количественные признаки описывались в виде минимального ( $\mathrm{min})$, максимального (max), среднего значений (Mean), стандартного отклонения $(m)$; качественные признаки представлялись в виде долей (\%) и абсолютных чисел. Сравнение количественных признаков проводилось с помощью t-критерия Стьюдента. Сравнительный анализ качественных переменных проводился с помощью критерия $\chi^{2}$ и точного 2-стороннего критерия Фишера. Различия в показателях считались достоверными при $p<0,05$.

Для изучения факторов риска инфицирования определенными возбудителями ВП (энтеробактерии, Streptococcus pneumoniae, Haemophilus influenzae, M. pneumoniae, C. pneumoniae, L. pneumophila) была построена многофакторная логистическая регрессионная модель. В модели переменными интереса являлись следующие показатели: возраст (16-39 лет, 40-64 года, $\geq 65$ лет), пол, степень тяжести ВП (нетяжелая vs тяжелая), характер течения (осложненное vs неосложненное), наличие следующих сопутствующих заболеваний: хроническая сердечная недостаточность $(\mathrm{XCH})$, хронические болезни печени, алкоголизм, хронические болезни почек, цереброваскулярные заболевания, онкологические заболевания и / или хроническая обструктивная болезнь легких (ХОБЛ), наличие факторов риска легионеллезной ВП.

\section{Результаты и обсуждение}

В исследование были включены 326 пациентов с ВП в возрасте 18-87 лет (средний возраст - 43,0 \pm 19,9 лет). Наибольшую долю составили пациенты, госпитализированные в 3 ЛПУ: КБСМП - 142 $(43,6 \%)$, ГКБ - 89 (27,3\%), СВГ - 84 (25,8\%). В 300 $(92,0 \%)$ случаях при поступлении пациентов госпитализировали в терапевтическое / пульмонологическое отделение, в $26(8,0 \%)$ - в отделение реанимации и интенсивной терапии (ОРИТ). Демографиические характеристики пациентов представлены в табл. 1.

В большинстве стационаров преобладали мужчины, доля которых была наиболее высокой в СВГ (98,8 \%). Пациенты СВГ отличались более молодым возрастом по сравнению с общей популяцией. Односторонняя ВП при рентгенологическом исследовании была выявлена в 272 / 326 (83,4 \%) случаев: у 113 / $142(79,6 \%), 78$ / 89 (87,9\%), 74 / 84 (88,1\%), 3 / 7 (42,9\%) и 4 / 4 (100\%) пациентов КБСМП, ГКБ № 1, СВГ, СОКБ и ЖДБ соответственно.

Тяжелая ВП была зарегистрирована у 63 (19,3 \%) пациентов, варьируясь по ЛПУ от 0 до 28,6 \% (табл. 1). Удельный вес пациентов с осложнениями в среднем составил 49,1 \% (160 / 326) и был наименьшим среди пациентов СВГ - 9 / 84 (10,7 \%). Среди осложнений преобладали дыхательная недостаточность, плеврит и кровохарканье (рис. 1). Доля лиц с хроническими сопутствующими заболеваниями варьировалась от $10,7 \%$ (9 / 84) в СВГ до 71,4 \% (5 / 7) в СОКБ (табл. 1). Распространенность хронических сопутствующих заболеваний в различных ЛПУ представлена на рис. 2.

Таблица 1

Характеристика пациентов с ВП в многопрофильных стационарах Смоленска

\begin{tabular}{|c|c|c|c|c|c|c|c|c|c|}
\hline \multirow[t]{2}{*}{ лпу } & \multirow[t]{2}{*}{$n$} & \multicolumn{3}{|c|}{ Возраст, лет } & \multirow{2}{*}{$\begin{array}{c}\text { Доля мужчин, } \\
\%\end{array}$} & \multirow{2}{*}{$\begin{array}{c}\text { Тяжелая ВП, } \\
\%\end{array}$} & \multirow{2}{*}{$\begin{array}{c}\text { Осложненная ВП, } \\
\%\end{array}$} & \multirow{2}{*}{$\begin{array}{c}\text { Доля лиц } \\
\text { с сопутствующими, } \\
\text { заболеваниями, \%* }\end{array}$} & \multirow{2}{*}{$\begin{array}{c}\text { АБТ до госпи- } \\
\text { питализации, \% }\end{array}$} \\
\hline & & $\min$ & $\max$ & $M \pm m$ & & & & & \\
\hline КБСМП & 142 & 18,0 & 87,0 & $49,8 \pm 17,5$ & 78,9 & 26,8 & 64,8 & 70,4 & 26,8 \\
\hline ГКБ № 1 & 89 & 18,0 & 86,0 & $50,9 \pm 17,4$ & 68,5 & 18,0 & 59,6 & 69,7 & 47,2 \\
\hline СВГ & 84 & 18,0 & 74,0 & $22,9 \pm 10,9$ & 98,8 & 8,3 & 10,7 & 10,7 & 16,7 \\
\hline СОКБ & 7 & 18,0 & 77,0 & $42,6 \pm 20,2$ & 71,4 & 28,6 & 57,1 & 71,4 & 0 \\
\hline ждБ & 4 & 35,0 & 57,0 & $47,8 \pm 10,2$ & 100 & 0 & 100 & 25 & 25 \\
\hline Всего & 326 & 18,0 & 87,0 & $43,0 \pm 19,9$ & 80,7 & 19,3 & 49,1 & 54,3 & 29,1 \\
\hline
\end{tabular}

Примечание: * - хронические сопутствующие заболевания, влияющие на прогноз (ХСН, хронические болезни печени и почек, алкоголизм, цереброваскулярные заболевания, онкологические заболевания, ХОБЛ). 


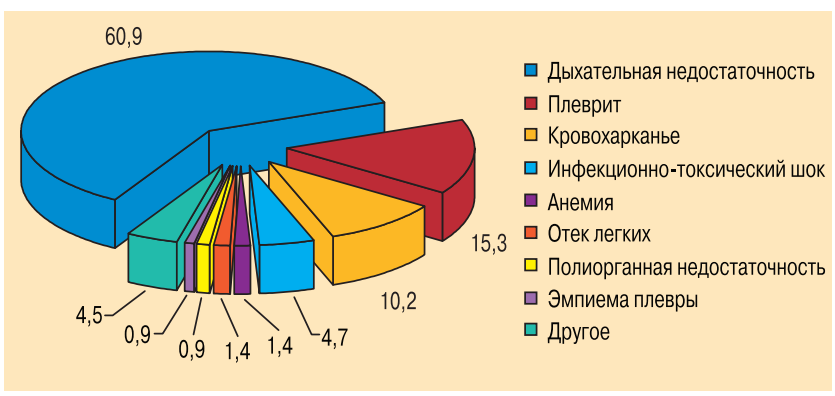

Рис. 1. Структура осложнений (\%) у госпитализированных пациентов с ВП в многопрофильных стационарах Смоленска, $n=215$

Всего 190 (58,3 \%) пациентов на момент включения в исследования курили, средний стаж курения составил 20,5 $\pm 17,4$ лет, $37(11,3 \%)$ - курили в прошлом (стаж $-21,4 \pm 15,8$ лет). Доля курильщиков в ГКБ № 1 составила 45 / 89 (50,6\%), в СВГ - 63 / 84 (75\%), в КБСМП - 79 / 142 (55,6 \%), в СОКБ - 3 / 7 (42,9\%).

Известные факторы риска легионеллезной инфекции были выявлены в 97 / 326 (29,8 \%) случаев, в т. ч. у $31 / 89(34,8 \%), 49$ / 84 (58,3\%), 1 / 4 (25,0 \%), 14 / $142(9,9 \%)$ и 2 / 7 (28,6 \%) пациентов ГКБ №1, СВГ, ЖДБ, КБСМП и СОКБ соответственно. Среди факторов риска наиболее часто встречались групповой характер заболевания - у 44 (13,5 \%) и недавнее путешествие - у 33 (10,1\%) пациентов.

АБТ на амбулаторном этапе применялась 95 / 326 $(29,1$ \%) пациентов; в структуре назначавшихся АМП преобладали амоксициллин и амоксициллин / клавуланат, которые использовались в 39 / 108 $(36,1 \%)$ и 20 / 108 (18,5 \%) случаях назначения данной группы препаратов соответственно. Доля пациентов, получавших АМП до госпитализации в различных ЛПУ, представлена в табл. 1.

Образцы для культурального исследования были получены у всех 326 пациентов. Структура образцов представлена на рис. 2. Наиболее частым материалом являлась мокрота, которую как единственный образец или в сочетании с другими исследовали у $312(95,7 \%)$ пациентов.

Всего было получено 325 образцов мокроты, у 300 / 312 (96,2 \%) пациентов исследовался 1, у 11 / 312 $(3,5 \%)-2$, у 1 / $312(0,3 \%)-3$ образца. При бактериоскопии критериям качественной мокроты соответствовали 161 / 325 (49,5 \%) образцов. Частота положительных результатов культурального иссле- дования мокроты при расчете на все образцы составила 81 / 325 (24,9 \%), при анализе только репрезентативных образцов - 81 / 161 (50,3\%).

Структура микроорганизмов, выявленных при бактериологическом исследовании мокроты, представлена в табл. 2. В структуре возбудителей преобладали H. influenzae и $S$. pneumoniae, на долю которых в монокультуре и в ассоциациях приходилось 66 / 81 $(81,5 \%)$ выделенных штаммов. БАЛ исследовался у 3 / 326 (0,9 \%) пациентов, всегда одновременно с другими клиническими образцами. Роста клинически значимых возбудителей при исследовании БАЛ не получено.

Клинически значимые возбудители из крови выделены в 9 / 43 (20,9 \%) случаях, в т. ч. в 4 / 9 случаев S. pneumoniae, в 3 / 9 - Klebsiella spp., по 1 случаю бактериемии было связано со $S$. aureus и E. cloaceae.

Аутопсийный материал получен у 5 / 326 (1,5\%) пациентов, у 3 из 5 - прижизненно также забирались клинические образцы (мокрота, кровь). Рост микроорганизмов при исследовании аутопсийного материала получен в 4 из 5 случаев, чаще в монокультуре (1-S. pneumoniae, $1-E$. coli, $1-K$. pneumoniae и $1-$ K. pneumoniae + Enterococcus spp.).

Бактериологическое исследование нескольких образцов выполнялось у 33 / 326 (10,1 \%) пациентов, чаще всего одновременно исследовались кровь и мокрота (рис. 3). В 16 / 28 (57,1 \%) случаев при исследовании крови и мокроты роста клинически значимых возбудителей не обнаружено, в 2 / 28 $(7,1 \%)$ - микроорганизмы выявлялись одновременно из крови и мокроты, в 3 / 28 (10,7 \%) - только из крови, в 7 / 28 (25\%) - только из мокроты. В 1 / 33 (3 \%) случае возбудитель был выявлен одновременно из мокроты, крови и биоптатов легочной ткани.

Этиологический диагноз ВП при бактериологическом исследовании был установлен у 90 / 326 $(27,6 \%)$ пациентов, в т. ч. у $23 / 89(25,8 \%)-$ в ГКБ № 1, 26 / 84 (31\%) - в СВГ, 39 / 142 (27,5\%) в КБСМП, 1 / 7 (14,3 \%) - в СОКБ, 1 / 4 - в ЖДБ. При нетяжелой ВП этот показатель составил 71 / 263 $(27,0 \%)$, при тяжелой - 19 / 63 (30,2 \%).

Предшествующая АБТ на амбулаторном этапе достоверно снижала частоту получения репрезентативных образцов мокроты (36,8 \% vs 53,9 \%), положительных результатов культурального исследова-

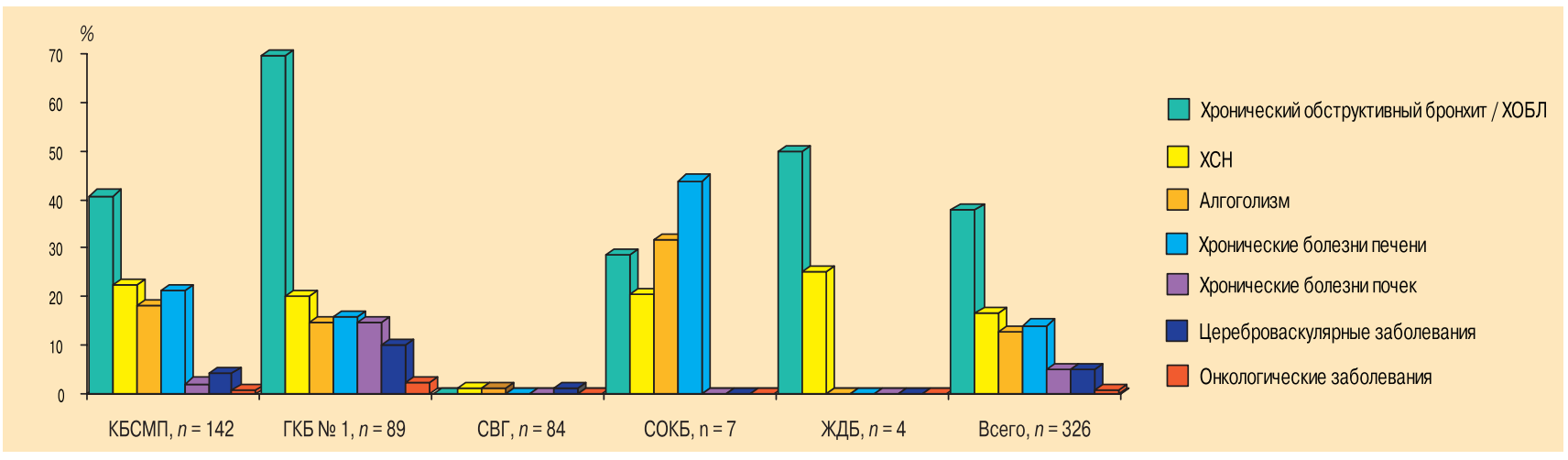

Рис. 2. Распространенность (\%) хронических сопутствующих заболеваний у госпитализированных пациентов с ВП в многопрофильных стационарах Смоленска 
Структура микроорганизмов, выделенных из мокроты у пациентов с ВП в многопрофильных стационарах Смоленска, \%

\begin{tabular}{|c|c|c|c|c|c|c|}
\hline Наименование микроорганизма & КБСМП, $n=35$ & ГКБ № $1, n=18$ & $\mathrm{CB} \Gamma, n=26$ & СОКБ, $n=1$ & ЖДБ, $n=1$ & Всего, $n=81$ \\
\hline H. influenzae & 22,9 & 33,3 & 65,4 & 1 & 1 & 40,7 \\
\hline S. pneumoniae & 31,4 & 33,3 & 15,4 & - & - & 25,9 \\
\hline H. influenzae + S. pneumoniae & 25,7 & - & 11,5 & - & - & 14,8 \\
\hline Escherichia coli & 2,9 & 11,1 & - & - & - & 3,7 \\
\hline Klebsiella pneumoniae & 5,7 & 5,6 & - & - & - & 3,7 \\
\hline H. influenzae + Staphylococcus aureus & & - & 7,7 & - & - & 2,5 \\
\hline$H$. influenzae $+K$. pneumoniae $+S$. pneumoniae & 5,7 & - & - & - & - & 2,5 \\
\hline K. pneumoniae + Proteus mirabilis & - & 5,6 & - & - & - & 1,2 \\
\hline Pseudomonas spp. & - & 5,6 & - & - & - & 1,2 \\
\hline Enterobacter cloacae & - & 5,6 & - & - & - & 1,2 \\
\hline E. cloacae $+K$. pneumoniae & 2,9 & - & - & - & - & 1,2 \\
\hline E. coli $+K$. pneumoniae & 2,9 & - & - & - & - & 1,2 \\
\hline
\end{tabular}

ния как мокроты (11,6\% vs 31,2\%), так и всех образцов в целом $(11,6 \%$ vs 34,2\%).

ПЦР выполнялась в 295 / 326 (90,5 \%) случаев, в т. ч. у 76 / $89(85,4 \%), 83$ / 84 (98,8 \%), 3 / 4 (75\%), 127 / $142(89,4 \%)$ и 6 / 7 (85,5\%) пациентов ГКБ № 1 , СВГ, ЖДБ, КБСМП и СОКБ соответственно. В структуре материала преобладала свободно отделяемая мокрота - 290 / 295 (98,3 \%).

Частота положительных результатов ПЦР составила 57 / 295 (19,3 \%), в т. ч. 12 / 127 (9,4 \%), 10 / 76
(13,2 \%), 32 / 83 (38,6 \%), 2 / 6 и 1 / 3 в КБСМП, ГКБ № 1, СВГ, СОКБ и ЖДБ соответственно. Частота положительных результатов ПЦР была выше у пациентов с нетяжелой ВП - 53 / 250 (21,2 \%) vs 4 / 45 $(8,9 \%)$; при тяжелой ВП, однако, разница не была статистически значимой $(p=0,05416)$.

В большинстве случаев выявлялась ДНК $M$. pneumoniae - 47 / 57 (82,5 \%), в т. ч. у 3 / 57 (5,3 \%) пациентов в ассоциации с C. pneumoniae. Доля L. pneumophila в структуре положительных результатов ПЦР

Таблица 3

Частота выявления возбудителей ВП при бактериологическом исследовании и ПЦР в многопрофильных стационарах Смоленска, \%

\begin{tabular}{|c|c|c|c|c|c|c|}
\hline Наименование микроорганизма & КБСМП, $n=127$ & ГКБ№ $1, n=76$ & $\mathrm{CB} \Gamma, n=83$ & СОКБ, $n=6$ & ЖДБ, $n=3$ & Bcero, $n=295$ \\
\hline Выявлен возбудитель, в т. ч.: & 37,1 & 34,2 & 59,0 & 3 & 2 & 42,7 \\
\hline M. pneumoniae & 25,5 & 30,8 & 34,7 & - & - & 29,4 \\
\hline H. influenzae & 17,0 & 19,2 & 16,3 & 1 & - & 17,5 \\
\hline S. pneumoniae & 23,4 & 23,1 & 8,2 & - & - & 16,7 \\
\hline H. influenzae + S. pneumoniae & 17,0 & - & 6,1 & - & - & 8,7 \\
\hline H. influenzae + M. pneumoniae & - & - & 12,2 & - & - & 4,8 \\
\hline L. pneumophila & - & - & 4,1 & 2 & 1 & 4,0 \\
\hline C. pneumoniae & - & 3,8 & 6,1 & - & - & 3,2 \\
\hline E. coli & 2,1 & 7,7 & - & - & - & 2,4 \\
\hline K. pneumoniae & 4,3 & 3,8 & - & - & - & 2,4 \\
\hline C. pneumoniae + H. Influenzae + M. pneumoniae & - & - & 4,1 & - & - & 1,6 \\
\hline E. coli $+K$. pneumoniae & 2,1 & 3,8 & - & - & - & 1,6 \\
\hline H. influenzae + K. Pneumoniae + S. pneumoniae & 4,3 & - & - & - & - & 1,6 \\
\hline H. influenzae + S. aureus & - & - & 4,1 & - & - & 1,6 \\
\hline C. pneumoniae $+H$. influenzae & - & - & 2,0 & - & - & 0,8 \\
\hline C. pneumoniae + M. pneumoniae & - & - & 2,0 & - & - & 0,8 \\
\hline E. cloacae $+K$. pneumoniae & 2,1 & - & - & - & - & 0,8 \\
\hline Enterococcus spp. $+K$. pneumoniae & 2,1 & - & - & - & - & 0,8 \\
\hline$K$. pneumoniae $+P$. mirabilis & - & 3,8 & - & - & - & 0,8 \\
\hline M. pneumoniae + S. pneumoniae & - & 3,8 & - & - & - & 0,8 \\
\hline Возбудитель не выявлен & 62,9 & 65,8 & 41,0 & 3 & 2 & 57,3 \\
\hline
\end{tabular}

http://www.pulmonology.ru 


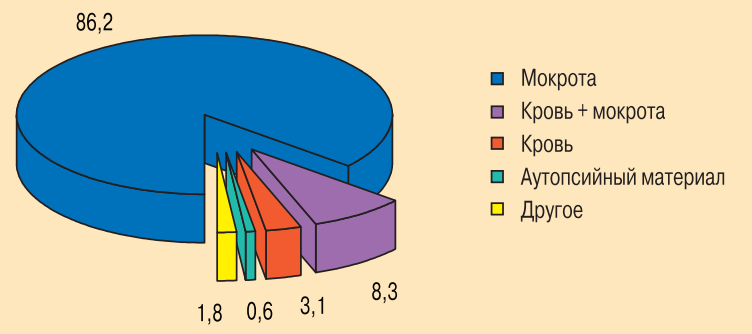

Рис. 3. Структура образцов (\%) для культурального исследования у пациентов с ВП в многопрофильных стационарах Смоленска, $n=326$

составила 5 / 57 (8,8 \%). Во всех случаях L. pneumophila являлась единственным возбудителем ВП. Известные факторы риска легионеллезной пневмонии присутствовали у 3 , а тяжелая ВП отмечалась у 2 из 5 пациентов.

Распространенность инфицирования $M$. рпеитоniae, C. pneumoniae и L. pneumophila среди обследованных пациентов представлена на рис. 4. Частота инфицирования $M$. pneumoniae и $C$. pneumoniae была выше среди пациентов с нетяжелой ВП и составила 45 / 250 (18,0 \%), 2 / 45 (4,4\%), 8 / 250 (3,2\%) и $0 \%$ соответственно, причем для M. pneumoniae эта разница была статистически значимой $(p=0,02218)$. Предшествующая АБТ на амбулаторном этапе достоверно не влияла на частоту выявления ДНК $M$. pneumoniae, $C$. pneumoniae и L . pneumophila методом ПЦР и составила 20 / 89 (22,5 \%) в группе, получавших АМП, и 37 / 206 (18,0 \%) среди пациентов, которые не получали АМП.

Частота выявления различных возбудителей ВП у пациентов, обследованных одновременно культуральным методом и методом ПЦР, представлена в табл. 3. Использование ПЦР наряду с культураль-

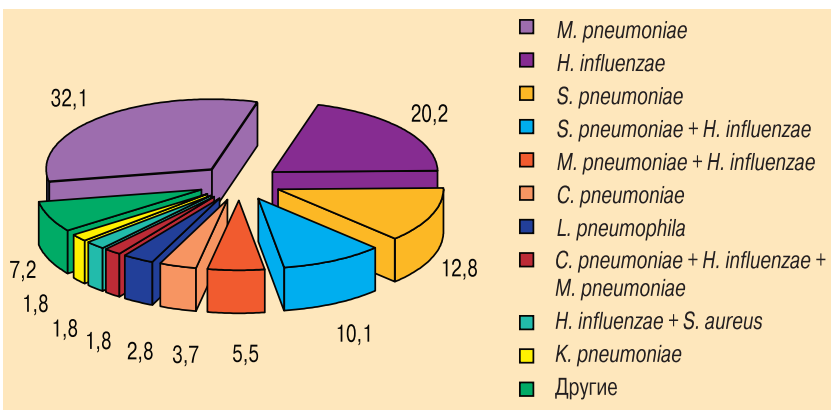

Рис. 5. Структура (\%) возбудителей нетяжелой ВП в многопрофильных стационарах Смоленска, $n=109$

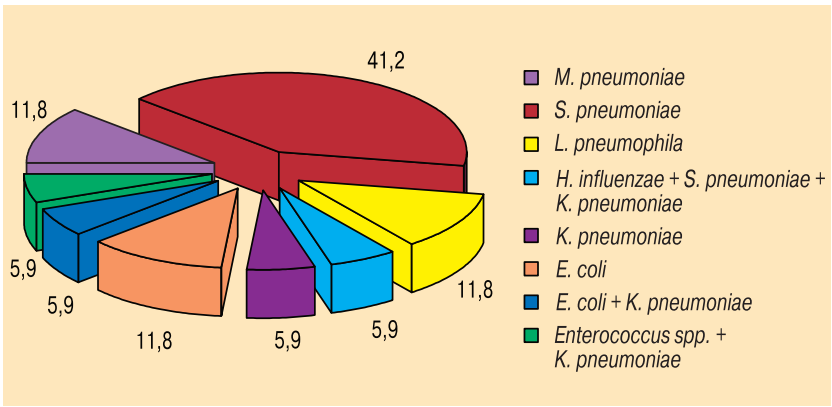

Рис. 6. Структура (\%) возбудителей тяжелой ВП в многопрофильных стационарах Смоленска, $n=17$

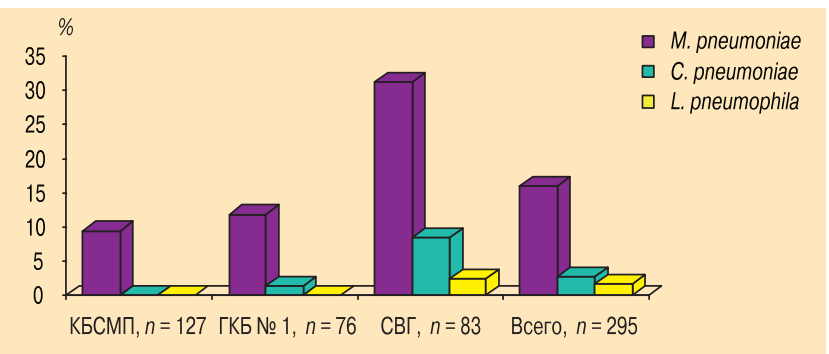

Рис. 4. Частота обнаружения (\%) ДНК М. рпеитопіае, C. pneumoniae и L. pneumophila методом ПЦР у пациентов с ВП в многопрофильных стационарах Смоленска

ным исследованием уменьшало частоту неустановленного этиологического диагноза ВП до 57,3 \%, особенно значимым это снижение было в СВГ.

Ассоциации микроорганизмов в структуре выделенных возбудителей встречались в 31 / 126 (24,6 \%) случаев, из них сочетание типичных и "атипичных" бактериальных возбудителей - в 10 / 126 (7,9 \%) случаев, наиболее часто выявлялись $H$. influenzae и M. pneumoniae. Анализ структуры возбудителей ВП с учетом степени тяжести представлен на рис. 5, 6.

Серологическое исследование выполнялось у 116 / $326(35,6 \%)$ пациентов, чаще всего в СВГ. Парные сыворотки были получены в 53 / 116 (45,7 \%) случаев. Первый образец сыворотки забирался в среднем на 1,2 $\pm 1,0$ день с момента госпитализации, 2-й - на $35,1 \pm 5,7$ дня после получения 1-го. Серологические маркеры, соответствующие острой инфекции выявлены в 83 / 116 (71,6 \%) случаев, в т. ч. в 10 / $19(52,6$ $\%)$ - в ГКБ № 1, в 32 / $40(80,0 \%)-$ в СВГ, в 39 / 55 $(70,9 \%)$ - в КБСМП, в 2 / 2 - в СОКБ (рис. 7). Частота инфицирования M. pneumonia, C. pneumophila и L. pneumophila при нетяжелой ВП составила 58 / 96 (60,4 \%), 25 / 96 (26,0 \%), 17 / 96 (17,7 \%), при тяжелой - 12 / 20 (60\%), 7 / 20 (35\%), 4 / 20 (20\%) соответственно. Достоверных различий в группах не наблюдалось.

ПЦР и серологическое исследование одновременно выполнялись у 112 / 326 (34,4 \%) пациентов, включенных в исследование, в т. ч. в 19 / 89 (21,3 \%), 40 / 84 (47,6 \%), 52 / 142 (36,6 \%) и 1 / 7 (14,3\%) случаев в ГКБ № 1, СВГ, КБСМП и СОКБ соответственно. Полное совпадение результатов ПЦР и серологического исследования отмечалось в 44 / 112 (39,3 \%) случаев. Совпадение результатов 2 методов исследо-

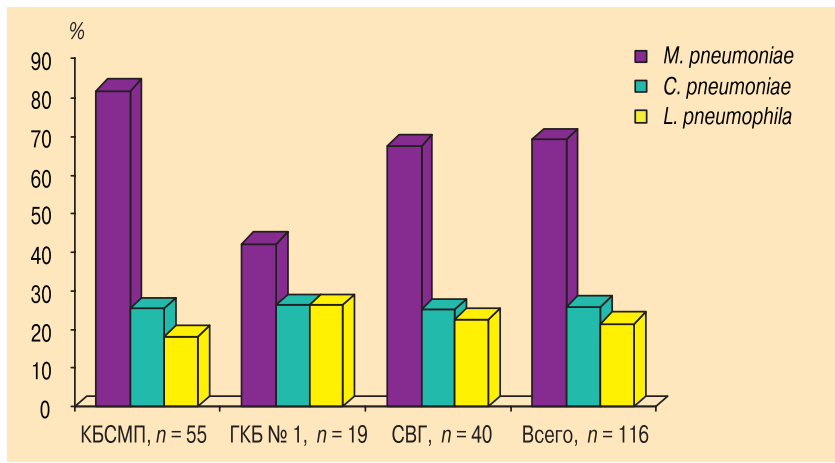

Рис. 7. Частота (\%) выявления серологических маркеров M. pnеиmoniae, C. pneumoniae и L. pneumophila-инфекции у пациентов с ВП в многопрофильных стационарах Смоленска 
вания было наиболее частым в случае выявления L. pneumophila и наименьшим - при исследовании на наличие маркеров инфицирования M. pneumoniae (табл. 4). Положительные результаты ПЦР на наличие антигенов $M$. pneumoniae не подтверждались серологическим методом в 2 / 21 (9,5 \%) случаев. При отрицательных результатах ПЦР серологические маркеры инфекции обнаруживались с частотой 18 / $109(16,6 \%), 29$ / $110(26,4 \%)$ и 50 / 91 (54,9\%) для L. pneumophila, C. pneumoniae и M. pneumoniae соответственно. Совпадение результатов ПЦР и серологического исследования для L. pneumophila, C. pneumoniae и M. pneumoniae составило 94 / 112 (83,9\%), 83 / $112(74,1 \%)$ и 60 / $112(53,6 \%)$ соответственно.

В ходе многофакторного регрессионного анализа значимыми факторами, влияющими на риск инфицирования энтеробактериями, являлись тяжесть ВП и наличие хронических сопутствующих заболеваний. Так, у пациентов с тяжелой ВП и при наличии хронических сопутствующих заболеваний риск выявления данной группы микроорганизмов возрастал с 1 до $23 \%$.

Факторами, значимо связанным с инфицированием $S$. pneumoniae, являлись мужской пол и хронические сопутствующие заболевания, повышающие вероятность пневомкокковой пневмонии при их сочетании с 1,9 до 21,4 \%; для $H$. influenzae значимой являлась тяжесть заболевания: при тяжелом течении вероятность выявления данного возбудителя составляла 1,6 \%, возрастая до $18,3 \%$ в случае нетяжелой ВП.

Вероятность ВП, вызванной M. pneumoniae, существенно возрастала при отсутствии хронических сопутствующих заболеваний и неосложненном течении заболевания, причем при их сочетании этот показатель достигал 46,8 \%.

Значимого влияния возраста, характера течения ВП, наличия осложнений, сопутствующих заболеваний и других факторов риска на вероятность выявления C. pneumoniae и L. pneumophila не выявлено.

У 309 / 326 (94,8 \%) пациентов к моменту выписки из ЛПУ наблюдалось полное разрешение клинических симптомов ВП или улучшение. Летальный исход чаще регистрировался при тяжелой ВП - 6 / 63 $(9,5 \%)$ случаев, по сравнению с нетяжелой - 3 / 263 $(1,1 \%) ;$ у данной категории пациентов также чаще отмечалось улучшение, нежели выздоровление - 41 / $63(65,1 \%)$ и 14 / $63(22,2 \%)$ vs 82 / $263(31,2 \%)$ и 172 / $263(65,4 \%)$.
Этиологическая диагностика ВП, по мнению ведущих зарубежных и отечественных специалистов, по-прежнему представляет существенную проблему, и даже современные методы позволяют выявить возбудитель заболевания только примерно в половине случаев. В ходе систематического обзора исследований, опубликованных в базе данных MEDLINE с января 1966 по 15 июня 1995 г., включавших в себя 33148 пациентов, этиология ВП оказалась установленной только в 66,2 \% случаев [13]. Частота ВП неустановленной этиологии среди госпитализированных пациентов с ВП в проспективных исследованиях, выполненных в разных странах мира в конце прошлого века, варьировалась от 17 до 48 \% [14-21].

Причины высокой частоты неустановленного этиологического диагноза при ВП могут быть различными - использование недостаточно чувствительных диагностических тестов, получение клинического материала на фоне АБТ, несоблюдение правил и сроков хранения и транспортировки образцов, что приводит к быстрой гибели "привередливых" микроорганизмов, таких как $S$. pneumoniae и H. influenzae и т. д. [22]. Кроме того, практически ежегодно список этиологических агентов ВП пополняется новыми возбудителями, которые могут до определенного времени оставаться неизвестными в связи с несовершенством методов микробиологической диагностики.

В нашем исследовании у всех 326 пациентов с ВП был получен материал для культурального исследования. Частота репрезентативных образцов мокроты составила 49,5 \%, этиологический диагноз ВП при бактериологическом исследовании был установлен в 27,2 \% случаев при нетяжелой и в $30,3 \%$ - при тяжелой ВП, при этом из респираторных образцов микроорганизмы выявлялись у 24,9 \% пациентов. Следует отметить, что при расчете частоты положительных результатов микробиологического исследования мокроты только на репрезентативные образцы этот показатель увеличивался в 2 раза, достигая 50,3\%.

Частота положительных результатов культурального исследования крови у пациентов с тяжелой ВП составила 20,9\%, что согласуется с результатами аналогичных международных и российских исследований. В недавно выполненном систематическом обзоре 13 исследований у госпитализированных пациентов с ВП частота положительных результатов гемокультуры варьировалась от 0 до 14 \% [23]. Среди пациентов, госпитализированных в ОРИТ, этот

Таблица 4

Сравнение результатов ПЦР и серологического исследования у пациентов с ВП в многопрофильных стационарах Смоленска

\begin{tabular}{|c|c|c|c|c|c|c|}
\hline \multirow[t]{3}{*}{ Наименование возбудителя } & \multicolumn{6}{|c|}{ Метод исследования } \\
\hline & \multirow[t]{2}{*}{$n$} & \multicolumn{2}{|c|}{ ПЦР(+) } & \multirow[t]{2}{*}{$n$} & \multicolumn{2}{|c|}{ ПЦР(-) } \\
\hline & & Серология (+), $n(\%)$ & Серология (-), n (\%) & & Серология (+), $n$ (\%) & Серология (-), n (\%) \\
\hline M. pneumoniae & 21 & $19(90,5)$ & $2(9,5)$ & 91 & $50(54,9)$ & $41(45,1)$ \\
\hline C. pneumoniae & 2 & $2(100)$ & - & 110 & $29(26,4)$ & $81(73,6)$ \\
\hline L. pneumophila & 3 & $3(100)$ & - & 109 & $18(16,5)$ & $91(83,5)$ \\
\hline
\end{tabular}


показатель в разных исследованиях составлял от 10 до $33 \%$ [24-27].

Следует отметить, что доля репрезентативных образцов мокроты, а также частота выявления клинически значимых возбудителей ВП как из мокроты, так и из любых исследуемых образцов при культуральном исследовании существенно снижалась у пациентов, получавших АБТ на амбулаторном этапе.

Негативное влияние предшествующего приема АМП на результативность бактериологического исследования клинических образцов, особенно на частоту выявления такого возбудителя, как $S$. pneumoniae, - общеизвестный факт, подтвержденный результатами как зарубежных, так и отечественных исследований [28-31]. Учитывая то, что существенная доля пациентов с ВП на амбулаторном этапе получают АБТ (в нашем исследовании этот показатель в одном из ЛПУ достигал 47,2 \%), у них целесообразно более широкое использование альтернативных методов диагностики, менее "чувствительных" к приему АМП, например экспресс-теста по выявлению пневмококковой антигенурии. Так, использование экспресс-теста в дополнение к традиционным методам этиологической диагностики в исследовании D. Genne et al. позволило выявить пневмококк дополнительно в $24 \%$ случаев ВП неизвестной этиологии [32]. Аналогичные данные были получены в одном из крупнейших проспективных исследований F.Gutierrez et al., где среди 269 пациентов с ВП и неустановленным возбудителем в $26 \%$ случаев была выявлена пневмококковая антигенурия [33].

В структуре микроорганизмов, выделенных из мокроты в нашем исследовании, 81,4 \% приходилось на 2 возбудителя - H. influenzae и $S$. pneumoniae, которые выявлялись в монокультуре или в ассоциации друг с другом (табл. 2). При этом необходимо отметить определенные различия в спектре возбудителей ВП как в разных ЛПУ, участвовавших в исследовании, так и в группах пациентов с различной степенью тяжести заболевания. Так, пневмококк был ведущим микроорганизмом у пациентов КБСМП, с одинаковой, по сравнению с H. influenzae, частотой он встречался в ГКБ № 1. В то же время в СВГ среди образцов с положительными результатами исследования подавляющее большинство приходилось на долю гемофильной палочки, которая в 65,4 \% случаев выявлялась в монокультуре, в 19,2 \% - в ассоциации с другими микроорганизмами, а пневмококк в монокультуре обнаруживался только у 15,4 \% пациентов. Энтеробактерии выявлены при исследовании мокроты только в КБСМП и ГКБ № 1, где на их долю приходилось 14,4 \% и 27,9 \% соответственно.

Существенные различия в профиле возбудителей, выявленные при исследовании мокроты в разных ЛПУ, можно объяснить особенностями пациентов, включенных в исследование. Так, в СВГ преобладали лица молодого возраста с нетяжелой ВП, распространенность ХСЗ у которых была очень низкой (табл. 1).

В то же время среди лиц, госпитализированных в КБСМП, доля тяжелой ВП достигала 26,8 \%, а та- кие сопутствующие заболевания, как ХСН, хронические болезни печени и алкоголизм, выявлялись в 22,5; 21,1 и 18,3\% случаев соответственно.

В ГКБ № 1 преобладали пациенты среднего и пожилого возраста, распространенность ХСЗ составляла 69,7 \%, среди них превалировали ХОБЛ, ХСН, хронические заболевания печени и почек (рис. 2).

При сравнении структуры возбудителей, выделенных из мокроты пациентов с нетяжелой и тяжелой ВП, следует отметить увеличение у последних доли пневмококка, энтеробактерий и уменьшение значимости $H$. influenzae, хотя эти данные должны интерпретироваться с осторожностью ввиду небольшого количества пациентов с положительными результатами культурального исследования. В то же время, эта тенденция подтверждается при оценке результатов бактериологического исследования крови и аутопсийного материала.

Так, при исследовании крови наиболее часто обнаруживаемым возбудителем являлся пневмококк, далее следует Klebsiella spp.; по 1 случаю бактериемии приходилось на S. aureus и E. cloacea. Энтеробактерии лидировали в структуре возбудителей фатальных пневмоний, причем в 2/3 случаев результаты исследования прижизненных образцов совпадали с исследованием аутопсийного материала, а в 1/3 случаев роста микроорганизмов при культуральном исследовании не наблюдалось. В ходе многофакторного регрессионного анализа тяжелое течение ВП в сочетании с ХСЗ увеличивало вероятность выявления энтеробактерий в 23 раза.

Анализируя результаты культурального исследования различных образцов, необходимо отметить в целом невысокую долю S. pneumoniae в этиологии ВП. И хотя пневмококк оставался лидирующим патогеном в структуре возбудителей ВП у лиц с тяжелым течением заболевания, а также в 2 ЛПУ, где преобладали пациенты среднего и пожилого возраста с сопутствующей патологией, частота его выявления была ниже, чем декларируется современными международными и национальными рекомендациями по ВП $[2,4,5]$. В то же время, тенденция уменьшения удельного веса $S$. pneumoniae в структуре возбудителей ВП отмечена и в других исследованиях, что активно обсуждается в настоящее время специалистами [34]. В качестве возможных причин такого феномена рассматриваются внедрение в клиническую практику пневмококковой вакцины (вакцинация полисахаридной вакциной взрослых и 7-валентной конъюгированной вакциной детей), рост доли лиц, получающих лечение АМП на амбулаторном этапе, ухудшение квалификации персонала микробиологических лабораторий, приводящее к снижению выявляемости "прихотливых" микроорганизмов, в частности пневмококка.

В нашем исследовании наиболее вероятной причиной низкой частоты выявления пневмококка можно считать высокую долю пациентов с предшествующей АБТ, причем в ее структуре преобладали амоксициллин и амоксициллин / клавуланат, характеризующиеся высокой антипневмококковой 
активностью. Так, среди пациентов, не получавших АБТ на амбулаторном этапе, доля пневмококка в этиологической структуре ВП возрастала в $\geq 2$ раза. Кроме того, исследуемая популяция пациентов отличалась от многих зарубежных исследований заметным преобладанием нетяжелой ВП (80,7 \%). Именно у этой категории пациентов традиционно более значимое место в этиологии ВП принадлежит респираторным вирусам и M. pneumoniae.

Следует отметить, что значимыми факторами, ассоциированными с вероятностью инфицирования $S$. pneumoniae, в нашем исследовании являлись мужской пол и ХС3, такие как ХCH, сахарный диабет, ХОБЛ, алкоголизм, хронические заболевания печени и почек. Их наличие повышало риск пневмококковой этиологии ВП с 1,9 до 21,4\%.

Еще одной особенностью, выявленной в настоящем исследовании, можно считать необычно высокую частоту встречаемости $H$. influenzae, особенно среди пациентов СВГ (табл. 2, 3). По результатам 10 исследований, выполненных в Великобритании, частота выявления гемофильной палочки варьировалась от 3,8 до 10,2 \%, прогрессивно снижаясь по мере роста тяжести ВП [5]. В ранее цитировавшемся исследовании P.G.P.Charles et al. среди госпитализированных пациентов с ВП в Австралии $H$. influenzae была обнаружена в 5,1 \% случаев, в Новой Зеландии среди бактериальных возбудителей ВП на гемофильную палочку приходилось $11 \%[3,35]$. В то же время высокая частота $H$. influenzae была характерна для ряда исследований, выполненных в Таиланде, Японии и Китае [36-38].

И.А.Гучев и соавт. при изучении этиологии ВП в сходной популяции пациентов из организованных коллективов показали, что наиболее частым возбудителем является пневмококК, далее следуют атипичные микроорганизмы; $H$. influenzae не выявлялась ни в одном случае [39].

Считается, что гемофильная палочка чаще встречается у пациентов с ХОБЛ и активных курильщиков [2, 9], хотя эта точка зрения экспертов не всегда подтверждается результатами исследований этиологии ВП у данной группы пациентов [40, 41]. В нашем исследовании доля активных курильщиков на момент включения в исследование составила 58,3\%, причем в СВГ этот показатель достигал $75 \% ; 11,3 \%$ курили прежде (средний стаж курения - 21,4 \pm 15,8 лет). Однако стаж курения у пациентов СВГ был относительно небольшим. Распространенность хронического бронхита / ХОБЛ составила в среднем 38 \%, варьируясь от 0 \% в СВГ до 69,7 \% в ГКБ № 1. Единственным фактором, который значимо ассоциировался с более высокой частотой выявления H. influenzae, являлось нетяжелое течение заболевания (в данном случае риск инфицирования этим микроорганизмом возрастал в 11,3 раза).

Третьей по частоте группой микроорганизмов, выявлявшихся при культуральном исследовании у пациентов с ВП, являлись энтеробактерии. Их доля была наиболее высокой в ГКБ № 1, что объясняется индивидуальными характеристиками пациен- тов - преобладание лиц среднего и пожилого возраста, высокая распространенность ХС3, а также наиболее высокой частотой использования АМП на догоспитальном этапе. Увеличение доли энтеробактерий было также характерно для пациентов с тяжелой ВП, особенно при фатальном исходе заболевания, где энтеробактерии выявлялись в 3 из 4 случаев.

Полученные данные в целом соответствуют результатам международных и ранее выполненных российских исследований [15, 42-44]. Так, при изучении этиологии ВП в Университетском госпитале г. Тарту K. pneumoniae была 3-м по частоте возбудителем, при этом ее доля достоверно возрастала среди лиц старше 60 лет и в случае предшествующей АБТ [42].

Наиболее частыми возбудителями тяжелой ВП у пациентов, не ответивших на стартовую АБТ и нуждающихся в ИВЛ, в исследовании C.L.Wu et al. были K. pneumoniae (25\%) и P. aeruginosa (22,5\%) [45]. $K$. pneumoniae являлась 2-м по частоте возбудителем ВП среди пациентов ОРИТ в работе F.Paganin et al., причем K. pneumoniae-ассоциированная пневмония сопровождалась достоверно более высокой летальностью по сравнению с пневмококковой [46]. В то же время в исследовании немецкой рабочей группы по ВП CAPNETZ (German CAP-Competence Network), включавшем 5130 пациентов, истинная распространенность энтреобактерий оказалась невысокой и составила 1,3\% [47]. Независимыми факторами риска инфицирования энтеробактериями являлись сопутствующие сердечно-сосудистые и цереброваскулярные заболевания [47]. Как показывают результаты нашего исследования, цереброваскулярные заболевания наиболее часто регистрировались среди пациентов ГКБ № 1, в этом же ЛПУ чаще всего выявлялись энтеробактерии.

Необходимо отметить, что ни в одном из случаев при культуральном исследовании не отмечено роста L. pneumophila, хотя данный возбудитель выявлялся некультуральными методами. Вероятно, это объясняется тем, что наибольшая доля образцов в нашем исследовании приходилась на свободно отделаемую мокроту, уступающую по чувствительности выявления L. pneumophila инвазивному клиническому материалу [48, 49].

Одной из отличительных характеристик нашей работы явилось применение для этиологической диагностики ВП наряду с культуральным исследованием метода ПЦР. Этот метод использовался у 295 / 326 $(90,5 \%)$ пациентов, включенных в исследование, при этом положительный результат отмечался в 19,3\% случаев.

Наиболее часто при исследовании методом ПЦР выявлялась $M$. pneumoniae, на ее долю в структуре ПЦР-позитивных результатов приходилось 77,2 \% (моноинфекция), в 5,3 \% случаев данный микроорганизм обнаруживался в ассоциации с C. pneumoniae, помимо случаев коинфекции с M. pneumoniae, у 8,8 \% пациентов выявлялась в качестве единственного возбудителя. Такая же доля в структуре "атипичных" микроорганизмов приходилась на L. pneumophila. 
Распространенность инфицирования М. рпеитоniae в целом составила $15,9 \%$, причем этот показатель существенно варьировался в разных ЛПУ и при ВП различной степени тяжести. Так, частота инфицирования М. pneumoniae в КБСМП и ГКБ № 1 была намного ниже, чем в СВГ - 9,4\% и $11,8 \%$ vs $31,3 \%$ соответственно. Кроме того, M. рпеитопіае выявлялась в 4 раза чаще среди пациентов с нетяжелой ВП по сравнению с группой тяжелого течения заболевания.

В целом полученные результаты подтверждают закономерности, наблюдавшиеся в других исследованиях, в частности преобладание $M$. pneumoniae у лиц молодого и среднего возраста с нетяжелой ВП и без серьезных сопутствующих заболеваний [5052]. Так, оба этих фактора в нашем исследовании были независимо связаны с более высокой вероятностью пневмонии микоплазменной этиологии, причем их сочетание повышало риск инфицирования данным возбудителем до 46,8 \%.

Кроме того, известно, что M. pneumoniae нередко вызывает вспышки ВП в организованных коллективах $[53,54]$. Поэтому распространенность M. pnеитоniae в нашем исследовании была самой высокой в СВГ, где подавляюшее число пациентов составляли военнослужащие срочной службы, причем M. pneumoniae в данном ЛПУ обнаруживалась значительно чаще, чем типичные бактериальные возбудители.

Частота выявления M. pneumoniae в остальных ЛПУ была менее значимой, но достаточно существенной, незначительно уступая $H$. influenzae и $S$. pneumoniae (табл. 3). В то же время на частоту встречаемости типичных бактериальных возбудителей значительное влияние оказывала предшествующая АБТ. Так, среди пациентов КБСМП и ГКБ № 1, не получавших АБТ на амбулаторном этапе, частота выявления $H$. influenzae и $S$. pneumoniae была намного выше - 35,5\% vs 18,7 \% и 29,6\% vs $8,1 \%$ соответственно (данные не представлены). Для "атипичных" возбудителей подобной закономерности не обнаружено.

Этот факт следует учитывать при интерпретации результатов исследования этиологии ВП, т. к. в популяции госпитализированных пациентов с высокой частотой предшествующей АБТ использование только культурального метода для выявления типичных бактериальных возбудителей, особенно таких, как пневмококк, может искажать истинную этиологическую структуру и, таким образом, формировать неверный подход к выбору АМП для эмпирической АБТ.

C. pneumoniae не являлась частым возбудителем ВП и выявлялась в среднем у 2,7 \% пациентов. Следует отметить, что 7 из 8 пациентов, инфицированных C. pneumoniae, лечились в СВГ, все случаи приходились на лиц с нетяжелым течением заболевания. Анализ частоты встречаемости данного возбудителя среди пациентов с ВП в опубликованных исследованиях свидетельствует о высокой вариабельности данного параметра и его зависимости от многих факторов - возраста пациентов, географической локализации, использовавшихся диагностических методов и критериев интерпретации их результатов [3, 55-58]. Считается, что в связи с отсутствием "золотого стандарта" этиологической диагностики истинная распространенность $C$. pneumoniae на сегодняшний день остается неизвестной [59]. Частое выявление одновременно с другими возбудителями, а также выздоровление пациентов, несмотря на прием АМП, не активных в отношении $C$. pneumoniae, оставляет открытым вопрос о самостоятельной этиологической значимости данного микроорганизма при ВП [5]. Так, например, в нашем исследовании C. pneumoniae в половине случаев выявлялась в ассоциации с другими микроорганизмами (M. pneumoniae, $H$. influenzae), 6 из 8 пациентов получали АМП, не активные в отношении данного возбудителя, при этом во всех случаях отмечалось клиническое выздоровление.

Одной из задач нашего исследования являлось изучение распространенности L. pneumophila среди возбудителей ВП, т. к. сведения о частоте спорадических случаев болезни легионеров в РФ практически отсутствуют. Вместе с тем высокая вариабельность частоты встречаемости данного возбудителя в разных географических регионах не позволяет экстраполировать на Россию данные, полученные в зарубежных исследованиях [56].

Инфицирование L. pneumophila было выявлено методом ПЦР в 5 из 295 случаев, что составило 1,7 \%, по 2 из них приходилось на СВГ и СОКБ, в 1 случае микроорганизм был выявлен в ЖДБ. В 2 из 5 случаев легионеллезная ВП характеризовалась нетяжелым течением; известные факторы риска, такие как недавнее путешествие, проживание в гостинице, наличие кондиционера дома или на работе также выявлялись у 3 пациентов. Во всех случаях L. pneumophila была единственным возбудителем ВП, что является отличительной чертой данного микроорганизма.

Следует отметить, что известные факторы риска легионеллезной инфекции присутствовали в достаточно большом проценте случаев и в общей популяции $(29,8 \%)$, что свидетельствует о недостаточно высокой специфичности анамнестических данных в дифференциальной диагностике болезни легионеров и ВП другой этиологии. Наши результаты подтверждаются и другими работами, в ходе которых попытки разработать клинико-лабораторные шкалы для идентификации легионеллезной ВП на момент поступления пациента в ЛПУ оказались не очень успешными [60-62].

В то же время обращает на себя внимание тот факт, что у 4 пациентов, которые в качестве стартовой терапии данного эпизода ВП получали $\beta$-лактамные антибиотики, не активные в отношении L. pneumophila, отсутствовала положительная динамика и потребовалась коррекция режима АБТ.

Учитывая низкую частоту встречаемости L. pneumophila в общей популяции госпитализированных пациентов, возможно, именно в группе лиц, не отвечающих на стартовую терапию $\beta$-лактамными АМП при их адекватном выборе, в случае нетяжелой ВП целесообразно проведение дополнительных скрининговых обследований, направленных на выявле- 
ние L. pneumophila (экспресс-тест на легионеллезную антигенурию, ПЦР и др.).

Интересно отметить, что у 24,6\% пациентов с положительными результатами культурального исследования и / или ПЦР выявлялось $\geq 2$ возбудителей, в т. ч. в 7,9 \% случаев - комбинация типичных и "атипичных" микроорганизмов. Среди последней группы преобладало сочетание M. pneumoniae и H. influenzae.

Частота ВП "смешанной" этиологии в нашем исследовании была более высокой, чем в аналогичных зарубежных работах, преимущественно за счет более частого выявления ассоциаций типичных бактериальных возбудителей [3]. Так, например, в работе $A$. de Roux et al. на долю ВП смешенной этиологии у госпитализированных пациентов приходилось $13 \%$, из них в $15 \%$ случаев выявлялись комбинации типичных и "атипичных" микроорганизмов [63].

Этот факт можно объяснить сложностью интерпретации результатов культурального исследования мокроты, которая в нашем случае являлась основным образцом для бактериологического исследования. Очевидно, что в ряде случаев выявленные при посеве мокроты бактерии, относящиеся к категории условнопатогенных, могут быть как возбудителями, так и "микробами-свидетелями", контаминирующими мокроту при ее прохождении через полость рта и верхние дыхательные пути. В то же время сопоставление результатов бактериоскопии мокроты с данными культурального исследования мокроты в нашем наблюдении свидетельствует о совпадении их результатов в 17 из 19 (89,5\%) случаев.

Помимо ПЦР у части пациентов с целью выявления "атипичных" микроорганизмов выполнялось иммуносерологическое исследование. Серологические маркеры острой инфекции обнаружены в 71,6 \% исследованных сывороток, наиболее частым возбудителем являлась M. pneumoniae (рис. 7).

Следует отметить, что существенных различий в частоте выявления иммунологических маркеров микоплазменной и легионеллезной инфекции между группами пациентов с тяжелой и нетяжелой ВП не наблюдалось; антитела к C. pneumoniae в диагностическом титре даже чаще обнаруживались среди лиц с тяжелым течением заболевания.

Существенный интерес представляет сравнение результатов ПЦР и серологического исследования, выполнявшееся у 112 пациентов. Как показывает наше исследование, полное совпадение результатов 2 методов отмечалось только в 39,3 \% случаев, при этом, если рассматривать ПЦР как "референтный" метод, то для ИФА были характерны как ложноположительные, так и ложноотрицательные результаты.

Положительные результаты ПЦР подтверждались ИФА во всех случаях при выявлении $C$. pneumoniae и L. pneumophila, в то же время у 2 из 21 ПЦР-позитивных пациентов с M. pneumoniae иммунологического ответа не наблюдалось. Отрицательный результат исследования в данном случае, возможно, связан с 2 факторами: исследованием одиночных сывороток и получением образцов в достаточно ранние сроки с момента появления симптомов заболевания - на 6-й и 7-й день соответственно. При отрицательном результате ПЦР чаще всего выявлялись серологические маркеры инфицирования $M$. pneumoniae $(54,9 \%)$, далее следовала C. pneumoniae; этот показатель был наименьшим для L. pneumophila (16,5\%).

Проблемы с чувствительностью и специфичностью серологических методов диагностики инфекций, вызванных "атипичными" возбудителями общеизвестный факт. Они могут быть связаны как с самим тестом и ошибками, совершаемыми в процессе постановки и интерпретации его результатов, так и с особенностями иммунологического ответа пациента и сроками получения образцов сыворотки для исследования.

Так, например, при сравнении 12 различных коммерчески доступных тест-систем у пациентов с подтвержденной микоплазменной инфекцией была показана их чрезвычайно вариабельная чувствительность и специфичность [64].

Применительно к результатам нашего исследования можно говорить о том, что использованием тестсистем Sero MP $\alpha$ IgM, Sero MP $\alpha \operatorname{IgA}$ и Sero MP $\alpha$ IgG SAVYON DIAGNOSTICS (Израиль) может приводить к высокому проценту ложноположительных результатов. В пользу данного утверждения, в частности, свидетельствует высокая частота обнаружения иммунологических маркеров микоплазменной инфекции у пациентов с тяжелой ВП, что весьма нетипично для данного возбудителя.

В отношении $C$. pneuminiae при исследовании образцов сыворотки результаты ПЦР-диагностики во всех случаях подтверждались ИФА, однако частота положительных серологических "находок" при отрицательных результатах ПЦР также была достаточно высокой и составила 26,4 \% (табл. 4). Это подтверждает мнение многих экспертов о том, что на сегодняшний день не существует надежных методов серологической диагностики хламидийной респираторной инфекции, в связи с этим их применение в клинической практике должно быть ограничено. Так же как и при микоплазменной инфекции, в качестве приоритетных на сегодняшний день рассматриваются МАНК (метод амплификации нуклеиновых кислот) и другие методы детекции антигенов C. pneuminiae, что связано с их более высокой специфичностью [5].

Результаты исследования в отношении L. pneumophila продемонстрировали наиболее высокий процент корреляции ПЦР и серологического метода исследования, хотя среди 16,5 \% "серопозитивных" случаев нельзя исключить наличие ложноположительных результатов, особенно с учетом того факта, что у ряда пациентов этой группы одновременно выявлялись признаки острой инфекции, вызванной другими "атипичными" микроорганизмами. Как известно, данная ситуация не характерна для легионеллезной пневмонии [65].

В нашей работе для диагностики L. pneumophila не использовался широко распространенный в мире экспресс-метод выявления легионеллезной антигенурии в связи с отсутствием официального статуса 
регистрации в РФ на момент проведения исследования. В то же время следует отметить, что доступные в настоящее время коммерческие экспресс-тесты разработаны с целью выявления L. pneumophila 1-й серогруппы, которая вызывает наибольшую долю случаев легионеллеза, ассоциированного с путешествиями [49]. Этот тест может уступать по чувствительности ПЦР в диагностике спорадических случаев болезни легионеров [66].

\section{Выводы}

1. Наиболее частыми бактериальными возбудителями ВП в стационарах Смоленска являлись $M$. pneumoniae, $H$. influenzae и $S$. pneumoniae; на их долю (в виде монокультуры и ассоциаций) приходилось 77,9 \% случаев пневмонии установленной этиологии.

2. Ведущими возбудителями тяжелой ВП являлись $S$. pneumoniae $(41,2 \%)$ и энтеробактерии $(23,6 \%)$, для нетяжелой - характерен высокий удельный вес M. pneumoniae $(32,1 \%)$ и $H$. influenzae $(20,2 \%)$.

3. Распространенность инфицирования L. pneumophila пациентов с ВП была низкой $(1,7 \%)$ и не зависела от наличия известных факторов риска легионеллезной инфекции.

4. Факторами, достоверно повышающими вероятность инфицирования $S$. pneumoniae, у госпитализированных пациентов с ВП были мужской пол и хронические сопутствующие заболевания; энтеробактериями - наличие хронических сопутствующих заболеваний и тяжелое течение пневмонии; H. influenzae - нетяжелая пневмония; M. pneumoniae - отсутствие осложнений и хронических сопутствующих заболеваний.

\section{Заключение}

Выполненное проспективное клинико-микробиологическое исследование является одним из первых в России, в ходе которого была изучена структура бактериальных возбудителей ВП у взрослых пациентов в различных стационарах Смоленска с использованием современных методов микробиологической диагностики, включая ПЦР.

Наиболее частыми бактериальными возбудителями ВП среди лиц с установленным этиологическим диагнозом являлись M. pneumoniae, S. pneumoniae и $H$. influenza, однако их удельный вес, также как и значимость более редко выявлявшихся энтеробактерий, существенно варьировались среди пациентов с различной степенью тяжести заболевания и в отдельных ЛПУ, участвовавших в исследовании. Эти различия, также как и наличие факторов риска инфицирования определенными возбудителями, необходимо учитывать при планировании эмпирической АБТ ВП.

Низкая частота выявления L. pneumophila может свидетельствовать о невысокой актуальности легионеллезной пневмонии в центральном регионе и неоправданности рутинного скрининга на данный микроорганизм среди госпитализированных пациентов с ВП.

Полученные нами данные по структуре бактериальных возбудителей ВП в целом согласуются с результатами международных исследований. В тоже время необходимо отметить ряд особенностей, которые требуют обсуждения и, возможно, дополнительных исследований. Одной из них является низкий удельный вес $S$. pneumoniae. Наиболее вероятным объяснением данного факта служит высокая частота АБТ на амбулаторном этапе, существенно снижающая результативность культурального исследования мокроты у госпитализированных пациентов, в первую очередь - частоту выявления S. pneumoniae. Это свидетельствует о целесообразности более широкого использования в стационарах Смоленска альтернативных культуральному методов этиологической диагностики ВП, в частности экспресс-теста на пневмококковую антигенурию.

Еще одной особенностью нашего исследования можно считать высокую частоту выявления $H$. influenzae. Вероятно, эта "находка" требует дополнительных исследований, предполагающих использование в качестве клинического материала вместо мокроты инвазивных респираторных образцов (БАЛ и др.), которые позволят более четко разграничить истинную инфекцию, вызываемую $H$. influenzae, от микробной колонизации.

\section{Литература}

1. Государственный доклад о состоянии здоровья населения Российской Федерации в 2003 году. М.: ГЭОТАРМедиа; 2003.

2. Внебольничная пневмония у взрослых: практические рекомендации по диагностике, лечению и профилактике у взрослых / Чучалин А.Г., Синопальников А.И., Страчунский Л.С. и др. М.: Атмосфера; 2006.

3. Charles P.G.P., Whitby M., Fuller A.J. et al. The etiology of community-acquired pneumonia in Australia: why penicillin plus doxycycline or a macrolide is the most appropriate therapy. Clin. Infect. Dis. 2008; 46: 1513-1521.

4. Mandell L.A., Wunderink R.G., Anzueto A. et al. IDSA / ATS Consensus Guidelines on the management of communityacquired pneumonia in adults. Clin. Infect. Dis. 2007; 44 (Suppl. 2): S27-S72.

5. Lim W.S., Baudouin S.V., George R.C. et al. BTS guidelines for the management of community-acquired pneumonia in adults: update 2009. Thorax 2009; 64: iii1-iii55.

6. Зубков М.Н. Сбор, транспортировка биологического материала и трактовка результатов микробиологических исследований. Клин. микробиол. и антимикроб. химиотер. 2004; 6 (2): 143-154.

7. Середкина М.А., Кречикова О.И., Сухорукова М.В. Микробиологическое исследование аутопсийного материала и интерпретация его результатов. Клин. микробиол. и антимикроб. химиотер. 2000; 2 (2): 79-85.

8. Зубков М.Н. Микробиологическая диагностика при легочных заболеваниях. В кн.: Чучалин А.Г. (ред.). Респираторная медицина. М.: ГЭОТАР-Медиа; 2007; т. 1: $238-252$.

9. Зубков М.Н., Стецюк О.У., Козлов Р.С., Страчунский Л.С. Этиология и микробиологическая диагностика внебольничных пневмоний. В кн.: Чучалин А.Г., Сино- 
пальников А.И., Чернеховская Н.Е. (ред.). Пневмония. М.: Экономика и информатика; 2002. 9-48.

10. Available from: http://www.interlabservice.ru/catalog/reagents

11. Available from: http://www.savyondiagnostics.com

12. Available from: http://www.vircell.com

13. Fine M.J., Smith M.A., Carson C.A. et al. Prognosis and outcomes of patients with community-acquired pneumonia. A meta-analysis. J.A.M.A. 1996; 275:134-141.

14. Marston B.J., Plouffe J.F., File T.M.Jr. et al. Incidence of community-acquired pneumonia requiring hospitalization: results of a population-based active surveillance study in Ohio. Arch. Intern. Med. 1997; 157: 1709-1718.

15. Park D.R., Sherbin V.L., Goodman M.S. et al. The aetiology of community-acquired pneumonia at an urban public hospital: influence of immunodeficiency virus infection and initial severity of illness. J. Infect. Dis. 2001; 84: 268-277.

16. Miyashita N., Fukano H., Niki Y. et al. Aetiology of community-acquired pneumonia requiring hospitalization in Japan. Chest 2001; 119: 1295-1296.

17. Ruiz-Gonzalez A., Falguera M., Nogues A. et al. Is Streptococcus pneumoniae the leading cause of pneumonia of unknown aetiology? A microbiologic study of lung aspirates in consecutive patients with community-acquired pneumonia. Am. J. Med. 1999; 106: 385-390.

18. Luna C.M., Famiglietti A., Absi R. et al. Communityacquired pneumonia: aetiology. epidemiology. and outcome at a teaching hospital in Argentina. Chest 2000; 118: 1344-1354.

19. Scott J.A., Hall A.J., Muyodi C. et al. Aetiology, outcome, and risk factors for mortality among adults with acute pneumonia in Kenya. Lancet 2000; 355: 1225-1230.

20. Lim W.S., MacFarlane J.T., Boswell T.C.J. et al. Study of community acquired pneumonia aetiology in adults admitted to hospital: implications for management guidelines. Thorax 2001; 56: 296-301.

21. Wattanathum A., Chaoprasong C., Nunthapisud P. et al. Community-acquired pneumonia in southeast Asia. Chest 2003; 123: 1512-1519.

22. Davidson R.J., Macdonald K.S. Laboratory diagnosis of community-acquided pneumonia. In: Marrie T.J., ed. Community-acquired pneumonia. New York: Kluwer Academic / Plenum Publishers; 2001. 35-43.

23. Afshar N., Tabas J., Afshar K. et al. Blood cultures for community-acquired pneumonia: are they worthy of two quality measures? A systematic review. J. Hosp. Med. 2009; 4: $112-123$

24. Rello J., Quintana E., Aussina V. et al. A three-year study of severe community-acquired pneumonia with emphasis on outcome. Chest 1993; 103: 232-235.

25. Almirall J., Mesalles E., Klamburg J. et al. Prognostic factors of pneumonia requiring admission to the intensive care unit. Chest 1995; 107: 511-516.

26. Pachon J., Prados M.D., Capote F. et al. Severe communityacquired pneumonia. Etiology, prognosis, and treatment. Am. Rev. Respir. Dis. 1990; 142: 369-373.

27. Ortqvist A., Sterner G., Nilsson J.A. Severe communityacquired pneumonia: factors influencing need of intensive care treatment and prognosis. Scand. J. Infect. Dis. 1985; 17: $377-386$.

28. Богданов М.В., Черненькая Т.В. Влияние "антибиотического" анамнеза на этиологию внебольничных пневмоний. Клин. фармакол. и тер. 1999; 8: 20-22.

29. Musher D.M., Montoya R., Wanahita A. Diagnostic value of microscopic examination of Gram-stained sputum and sputum cultures in patients with bacteremic pneumococcal pneumonia. Clin. Infect. Dis. 2004; 39: 165-169.
30. Рачина С.А., Иванчик Н.В., Кречикова О.И. и др. Влияние предшествующей антибактериальной терапии на результативность микробиологических исследований при внебольничной пневмонии. Клин. микробиол. и антимикроб. химиотер. 2007; 9 (Прил. 1): 35-36.

31. Glerant J.C., Hellmuth D., Schmit J.L. et al. Utility of blood cultures in community-acquired pneumonia requiring hospitalization: influence of antibiotic treatment before admission. Respir. Med. 1999; 93: 208-212.

32. Genne D., Siegrist H.H., Lienhard R. Enhancing the etiologic diagnosis of community-acquired pneumonia in adults using the urinary antigen assay (Binax NOW). Intern. J. Infect. Dis. 2006; 10: 124-128.

33. Gutierrez F., Rodriequez J.C., Ayelo A. et al. Evaluation of the immunochromatographic Binax NOW assay for detection of Streptococcus pneumoniae urinary antigen in a prospective study of community-acquired pneumonia in Spain. Clin. Infect. Dis. 2003; 36: 286-292.

34. Moellering R.C.Jr. The continuing challenge of lower respiratory tract infections. Clin. Infect. Dis. 2004; 38 (Suppl. 4): S319-S321.

35. Jennings L.C., Anderson T.P., Beynon K.A. et al. Incidence and characteristics of viral community-acquired pneumonia in adults. Thorax 2008; 63: 42-48.

36. Reechaipichitkul W., Lulitanond V., Sawanyawisuth K. et al. Etiologies and treatment outcomes for out-patients with community-acquired pneumonia (CAP) at Srinagarid Hospital. Khon Kaen. Tailand. South. Asian J. Trop. Med. Publ. Hlth 2005; 36: 1261-1267.

37. Yen M.-Y., Hu B.-S., Chen Y.-S. et al. A prospective etiologic study of community-acquired pneumonia in Taiwan. J. Formos. Med. Assoc. 2005; 104: 724-730.

38. Saito A., Kohno S., Matsushima T. et al. Prospective multicenter study of the causative organisms of communityacquired pneumonia in adults in Japan. J. Infect. Chemother. 2006; 12: 63-69.

39. Guchev I.A., Yu V.L., Sinopalnikov A.I. et al. Management of nonsevere pneumonia in military trainees with the urinary antigen test for Streptococcus pmeumoniae: an innovative approach to target therapy. Clin. Infect. Dis. 2005; 40: $1608-1615$.

40. Gutierrez F., Masia M., Rodriguez J.C. et al. Epidemiology of community-acquired pneumonia in adult patients at the dawn of the $21^{\text {st }}$ century: a prospective study on the Mediterranean coast of Spain. Clin. Microbiol. Infect. 2005; 11: 788-800.

41. Torres A., Dorca J., Zalacain R. et al. Community-acquired pneumonia in chronic obstructive pulmonary disease: A Spanish multicenter study. Am. J. Respir. Crit. Care Med. 1996; 154: 1456-1461.

42. Leesik H., Ani U., Juhani A. et al. Microbial pathogens of adult community-acquired pneumonia in Southern Estonia. Medicina (Kaunas) 2006; 42: 384-394.

43. Синопальников А.И., Тартаковский И.С., Миронов М.Б. Внебольнично приобретенная пневмония: этиологический диагноз. Антибиотики и химиотер. 1997; 42 (10): $38-43$.

44. Савинова Т.Л., Бейкин Я.Б., Шилова В.П. и др. Практический опыт лабораторной диагностики внебольничных пневмоний. Клин. микробиол. и антимикроб. химиотер. 2009; 11 (1): 79-85.

45. Wu C.L., Chan M.C., Chang G.C. et al. Eliology and cytokine expression in patients requiring mechanical ventilation due to severe community-acquired pneumonia. J. Formos. Med. Assoc. 2006; 105: 49-55. 
46. Paganin F., Lilienthal F., Bourdin A. et al. Severe community-acquired pneumonia: assessment of microbial aetiology as mortality factor. Eur. Respir. J. 2004; 24: 779-785.

47. von Baum H., Welte T., Marre R. et al. Community-acquired pneumonia through Enterobacteriaceae and Pseudomonas aeruginosa: diagnosis. incidence and predictors. The German Competence Network for Community-acquired pneumonia (CAPNETZ). Eur. Respir. J. 2010; 35 (3): 598-605.

48. Практические рекомендации по диагностике и лечению легионеллезной инфекции, вызванной Legionella pneumophila серогруппы 1: Пособие для врачей / Чучалин А.Г., Синопальников А.И., Тартаковский И.С. и др. M.; 2009.

49. Diederen B.M.W. Legionella spp. and Legionnaires' disease. J. Infect. 2007; xx: 1-12.

50. von Baum H., Welte T., Marre R. et al. Mycoplasma pneumoniae pneumonia revisited within the German Competence Network for Community-acquired pneumonia (CAPNETZ). BMC Infect. Dis. 2009; 9: 62.

51. Miyashita N., Ouchi K., Kawasaki K. et al. Mycoplasma pneumoniae pneumonia in the elderly. Med. Sci. Monit. 2008; 14 (8): CR387- CR391.

52. Ausina V., Coll P., Sambeat M. et al. Prospective study on the etiology of community-acquired pneumonia in children and adults in Spain. Eur. J. Clin. Microbiol. Infect. Dis. 1988; 7 : 342-347.

53. Gray G.C., Duffi L. B., Paver R.J. et al. Mycoplasma pneumoniae: a frequent cause of pneumonia among U.S. Marines in southern California. Milit. Med. 1997; 162: $524-526$

54. Hyde T.B., Gilbert M., Schwartz S.B. et al. Azithromycin prophylaxis during a hospital outbreak of Mycoplasma pneumoniae pneumonia. J. Infect. Dis. 2001; 187: 907-912.

55. Wellinghausen N., Straube E., Freidank H. et al. Low prevalence of Chlamydia pneumoniae in adults with communityacquired pneumonia. Int. J. Med. Microbiol. 2006; 296: 485-491.

56. Arnold F.W., Summersgill J.T., Lajoie A.S. et al. A worldwide perspective of atypical pathogens in community-acquired pneumonia. Am. J. Respir. Crit. Care Med. 2007; 175: $1086-1093$.

57. Macfarlane J., Holmes W., Gard P. et al. Prospective study of the incidence, aetiology and outcome of adult lower respiratory tract illness in the community. Thorax 2001; 56: $109-114$

58. Schneeberger P.M., Dorigo-Zetsma J.W., van der Zee A. et al. Diagnosis of atypical pathogens in patients hospitalized with community-acquired respiratory infection. Scand. J. Infect. Dis. 2004; 36: 269-273.

59. Kumar S., Hammerschlag M.R. acute respiratory infection due to chlamydia pneumoniae: current status of diagnostic methods. Clin. Infect. Dis. 2007; 44: 568-576.

60. Gupta S.K., Imperiale T.F., Sarosi G.A. Evaluation of the Winthrop-University Hospital criteria to identify Legionella pneumonia. Chest 2001; 120 (4): 1064-1071.
61. Fernandez-Sabe N., Roson B., Carratala J. et al. Clinical diagnosis of Legionella pneumonia revisited: evaluation of the Community-Based Pneumonia Incidence Study Group scoring system. Clin. Infect. Dis. 2003; 37: 483-489.

62. Yu V.L., Stout J.E. Community-acquired Legionnaires disease: implications for underdiagnosis and laboratory testing. Clin. Infect. Dis. 2008; 46: 1365-1367.

63. de Roux A., Ewig S., Garcia E. et al. Mixed communityacquired pneumonia in hospitalized patients. Eur. Respir. J. 2006; 27: 795-800.

64. Beersema M.F., Dirven K., van Dam A.P. et al. Evaluation of 12 commercial tests and the complement fixation test for Mycoplasma pneumoniae-specific immunoglobulin G (IgG) and IgM antibodies, with PCR used as the "gold standard". J. Clin. Microbiol. 2005; 43: 2277-2285.

65. Тартаковский И.С., Синопальников А.И. Легионеллез: роль в инфекционной патологии человека. Клин. микробиол. и антимикроб. химиотер. 2001; 3: 4-16.

66. Jespersen S., Sogard O.S., Fine M.J. et al. The relationship between diagnostic tests and case characteristics in Legionnaires' disease. Scand. J. Infect. Dis. 2009; 8: 1-8.

\section{Информация об авторах}

Рачина Светлана Александровна - к. М. Н., ассистент кафедры клинической фармакологии ГОУ ВПО "Смоленская государственная медицинская академия Федерального агентства по здравоохранению и социальному развитию"; тел.: (4812) 61-13-01; e-mail: Svetlana.Ratchina @antibiotic.ru

Козлов Роман Сергеевич - д. м. н., проф. ГОУ ВПО "Смоленская государственная медицинская академия Федерального агентства по здравоохранению и социальному развитию", директор НИИ антимикробной химиотерапии; тел.: (4812) 45-06-02; e-mail: Roman.Kozlov @antibiotic.ru

Шаль Евгений Петрович - специалист по клиническим исследованиям ООО "ППД Девелопмент"; тел.: (4812) 20-24-00; e-mail: shal@antibiotic.ru Устюжанин Иван Владимирович - врач-интерн Уз "Калужская областная больница", неврологическое отделение; тел.: (4842) 72-59-11; e-mail: ustivan@yandex.ru

Кречикова Ольга Ивановна - к. м. н., зав. лабораторией НИИ антимикробной химиотерапии; тел.: (4812) 45-06-02; e-mail: Olga.Kretchikova @antibiotic.ru

Иванчик Наталия Владимировна - к. м. н., врач-бактериолог НИИ антимикробной химиотерапии; тел.: (4842) 45-06-02; e-mail: Natali.Ivanchik @antibiotic.ru

Гудков Иван Валентинович - статистик НИИ антимикробной химиотерапии; тел.: (4812) 45-06-02; e-mail: Ivan.Gudkov@antibiotic.ru

Асафьева Олеся Юрьевна - зав. терапевтическим отделением Млпу "Клиническая больница скорой медицинской помощи"; тел.: (4812) 38-09-01

Гучев Игорь Анатольевич - к. м. н., начальник терапевтического отделения ФГУ "421-й Военный госпиталь Московского военного округа"; тел.: (4812) 27-11-96; e-mail: iguchev@gmail.com

Гуляева Светлана Архиповна - зав. пульмонологическим отделением мЛПУ "Первая городская клиническая больница"; тел.: (4812) 27-02-96 Бурдинская Юлия Владимировна - клинический фармаколог НУЗ "Отделенческая больница ст. Смоленск ОАО РЖД"; тел.: (4812) 39-58-22 Деленческая больница ст. Смоленск ОАО РЖД"; тел.: (4812) 39-58-22 "Центральный НИИ эпидемиологии Роспотребнадзора"; (495) 974-96-46; e-mail: syatsyshina@pcr.ru

Астахова Татьяна Станиславовна - к. б. н., научный сотрудник ФГУН "Центральный НИИ эпидемиологии Роспотребнадзора"; e-mail: astahova @pcr.ru

Бейкин Яков Борисович - д. м. н., проф., глав. врач МУ "Клинико-диагностический центр"; тел.: (343) 257-37-69

Беседина Лариса Германовна - зав. лабораторией МУ "Клинико-диагностический центр"; тел.: (343) 257-37-69 